\title{
DUKUNGAN KELUARGA YANG BAIK MENINGKATKAN KEPATUHAN MINUM OBAT PADA PASIEN SKIZOFRENIA DI POLIKLINIK RSU TANGERANG
}

\author{
Lailatul Fadilah*, H. Nasihin*, Lindawati*
}

\begin{abstract}
Abstrak
Data statistik Direktorat Keswa menunjukkan klien gangguan jiwa berat terbesar di Indonesia adalah skizofrenia yakni 70\% (Depkes RI, 2008) terjadi pada usia 18 sampai 45 tahun, tetapi ada juga berusia 11 sampai 12 tahun menderita skizofrenia. Hasil penelitian menunjukkan bahwa 25 persen sampai 50 persen pasien yang pulang dari rumah sakit jiwa tidak memakan obat secara teratur (Appleton dalam Keliat,1996). Tujuan penelitian ini adalah untuk mengetahui hubungan antara dukungan keluarga dengan kepatuhan minum obat pada pasien skizofrenia dengan desain penelitian cross sectional. Sampel penelitian berjumlah 81 responden yang datang berobat ke Poli Jiwa RSU Tangerang dengan teknik consecutive sampling. Analisa yang digunakan yaitu analisa univariat dan analisa bivariat menggunakan uji chi square dengan tingkat kemaknaan $(\alpha=0,05)$. Hasil uji statistik diperoleh nilai $\mathrm{p}=0.000$ maka dapat disimpulkan ada hubungan yang signifikan antara dukungan keluarga dengan kepatuhan minum obat. Dari hasil analisis diperoleh nilai odds ratio $(\mathrm{OR})=19.94$, artinya keluarga yang memberikan dukungan memiliki peluang 19.94 kali untuk anggota keluarga yang mengalami gangguan jiwa patuh minum obat.
\end{abstract}

\section{Kata Kunci : pasien skizofrenia, dukungan keluarga, kepatuhan minum obat}

\begin{abstract}
Statistical data show clients Directorate Keswa severe mental disorder is schizophrenia in Indonesia namely $70 \%$ ( MOH, 2008) occurred at the age of 18 to 45 years, but there are also 11 to 12 years old suffering from schizophrenia. Results showed that 25 percent to 50 percent of patients who come home from a mental hospital does not take medication regularly ( in Keliat Appleton, 1996 ). The purpose of this study was to determine the relationship between family support with medication adherence in schizophrenia patients with cross-sectional research design . Sample was 81 respondents who came went to Poly Life RSU Tangerang with consecutive sampling technique. The analysis used is univariate and bivariate analysis using chi square test with a significance level $(\alpha=0.05)$. Statistical test results obtained $p$ value $=0.000$, it can be concluded that there is a significant relationship between family support with medication adherence. From the results obtained by the analysis of the value of the odds ratio $(O R)=19.94$, meaning families have the opportunity to provide support 19.94 times for family members who experience mental illness to take medication adherent.
\end{abstract}

Keywords : schizophrenia patients, family support, drug compliance

*Jurusan Keperawatan Tangerang Politeknik Kesehatan Kemenkes Banten 


\section{Pendahuluan}

Data yang ditemukan oleh program pengobatan. Kikkert et al, WHO (2009) memperkirakan 450 juta (dalam Fakhrudin, 2012) berpendapat orang di seluruh dunia mengalami bahwa kepatuhan minum obat pada gangguan jiwa, dan kemungkinan pasien skizofrenia dapat dipengaruhi gangguan jiwa akan berkembang oleh efikasi minum obat, dukungan menjadi 25\% di tahun 2030. Sedangkan terhadap pasien, insight, efek samping prevalensi penderita gangguan jiwa obat dan sikap pasien. Hasil penelitian berat di Indonesia pada tahun 2007 menunjukkan bahwa 25 persen sampai sebesar 4,6 permil (1000 penduduk 50 persen pasien yang pulang dari Indonesia empat sampai lima rumah sakit jiwa tidak memakan obat diantaranya menderita gangguan jiwa secara teratur (Appleton dalam berat). Data statistik Direktorat Keswa Keliat,1996). Fleischacker (2003) menunjukkan klien gangguan jiwa menyatakan bahwa faktor yang berat terbesar di Indonesia adalah mempengaruhi kepatuhan terhadap skizofrenia yakni 70\% (Depkes RI, pengobatan pasien gangguan jiwa 2008). Angka prevalensi skizofrenia di antara lain individu, penyakit, obat Indonesia adalah 0,3 sampai 1 persen, yang dikonsumsi, petugas kesehatan, terjadi pada usia 18 sampai 45 tahun, dan lingkungan.

tetapi ada juga berusia 11 sampai 12 Dukungan sosial adalah tahun menderita skizofrenia. Apabila keadaan yang bermanfaat bagi individu penduduk Indonesia 200 juta jiwa, yang diperoleh dari orang lain yang maka diperkirakan sekitar 2 juta jiwa dapat dipercaya, sehingga seseorang menderita skizofrenia (Prabowo, 2010). Tingginya masalah tersebut akan tahu bahwa ada orang lain yang memperhatikan, menghargai, dan menunjukan bahwa masalah kesehatan jiwa merupakan salah satu masalah kesehatan masyarakat yang besar dibandingkan dengan masalah lainnya dimasyarakat (Depkes RI, 2008).

Kampman (dalam Fakhrudin, 2012) menemukan sekitar $25 \%$ pasien skizofrenia, psikosis maupun gangguan mental berat gagal dalam mematuhi mencintainya (Cohen \& Syme, dalam Setiadi, 2008). Keluarga merupakan bagian dari kelompok sosial. House (dalam Smet, 2004) membedakan lima dimensi dukungan sosial yang meliputi : dukungan emosional, dukungan penghargaan, dukungan instrumental, dukungan informatif, dan dukungan jaringan. Keluarga sebagai sumber 
dukungan sosial dapat menjadi bagian yang penting dalam penyembuhan penderita gangguan jiwa (Kumfo, dalam Viedeback, 2008). Individu yang mendapat sosial terbukti lebih sehat daripada individu yang tidak dapat dukungan sosial (Buchanan, 1995). Pasien yang tinggal sendirian secara umum mempunyai angka kepatuhan yang rendah dibanding mereka yang tinggal dalam lingkungan yang mendukung (Fleischacker, 2003)

Data kunjungan penderita gangguan jiwa yang berkunjung di poliklinik psikiatri RSU Tangerang terhitung tahun 2010 adalah 4377 kunjungan pasien rawat jalan tertulis dengan semua diagnosis gangguan jiwa, sedangkan data kunjungan terbaru dari awal bulan Januari-April 2011 tercatat 1684 kunjungan pasien gangguan jiwa yang melakukan rawat jalan di Poliklinik Psikiatri RSU Tangerang (Isti, 2011). Perumusan masalah pada penelitian ini adalah "Hubungan antara dukungan keluarga dengan kepatuhan minum obat pada pasien skizofrenia di Poliklinik Jiwa RSU Tangerang”. keluarga dengan kepatuhan minum obat pada pasien skizofrenia.

\section{Metode Penelitian}

Penelitian ini merupakan penelitian kuantitatif dengan menggunakan desain penelitian cross sectional. Data dianalisis menggunakan analisis univariat dan bivariat . Sampel penelitian berjumlah 81 responden yang datang berobat ke Poli Jiwa RSU Tangerang dengan teknik consecutive sampling. Alat pengumpulan data berupa kuesioner yang terdiri dari 12 pernyataan. Analisa yang digunakan yaitu analisa univariat dan analisa bivariat menggunakan uji chi square dengan tingkat kemaknaan $(\alpha=0,05)$ (Hastono, 2010).

\section{Hasil Penelitian}

A. Dukungan keluarga

Tabel 1. Distribusi responden menurut dukungan keluarga

\begin{tabular}{llcc}
\hline No & Dukungan Keluarga & Jumlah & $\begin{array}{c}\text { Persentase } \\
(\%)\end{array}$ \\
\hline 1 & Mendukung & 66 & 81,5 \\
2 & Tidak Mendukung & 15 & 18,5 \\
\hline & Total & 81 & 100 \\
\hline
\end{tabular}

Penelitian ini bertujuan untuk mengetahui hubungan antara dukungan 
B. Kepatuhan Minum Obat

Tabel 2. Distribusi responden menurut kepatuhan minum obat keluarga yang memberikan dukungan memiliki peluang 19.94 kali untuk anggota keluarga yang mengalami
No Kepatuhan minum Jumlah Persentase jiwa patuh minum obat. obat

\begin{tabular}{llcc}
\hline 1 & Patuh & 62 & Pemb5ahasan \\
2 & Tidak Patuh & 19 & 23,5 Hasil penelitian didapatkan \\
\hline & Total & 81 & 100 \\
\hline
\end{tabular}

C. Hubungan dukungan keluarga dan kepatuhan minum obat

Tabel 3.Distribusi responden menurut hubungan dukungan keluarga dan kepatuhan minum obat

$(81,5 \%)$ memberikan dukungan, kepatuhan minum obat anggota keluarga yang mengalami gangguan jiwa sebesar 62 responden (76,5\%). Hasil- uji statistik diperoleh nilai $\mathrm{p}=$ d.dero maka dapat disimpulkan ada hoboungan yang signifikan antara dukungan keluarga dengan kepatuhan

$\begin{array}{lllllll}\text { Mendukung } & 58 & 87,9 & 8 & 12,1 & 66 & 100\end{array}$

$\begin{array}{lllllll}\text { Tidak } & 4 & 26,7 & 11 & 73,3 & 15 & 100\end{array}$

Mendukung

$\begin{array}{lllllll}\text { Total } & 62 & 76,5 & 19 & 23,5 & 81 & 100\end{array}$ minum obat. Dari hasil analisis

Tabel diatas menggambarkan hasil diperoleah pula nilai odds ratio $(\mathrm{OR})=$ analisis hubungan antara dukungan keluarga dengan kepatuhan minum memberikan dukungan memiliki obat diperoleh bahwa ada 8 responden $(12,1 \%)$ yang mendukung namun tidak patuh minum obat. Sedangkan responden yang tidak mendukung ada 4 $(26,7 \%)$ yang patuh minum obat. Hasil uji statistik diperoleh nilai $\mathrm{p}=0.000$ maka dapat disimpulkan ada hubungan yang signifikan antara dukungan keluarga dengan kepatuhan minum obat. Dari hasil analisis diperoleh pula nilai odds ratio $(\mathrm{OR})=19.94$, artinya dari kelompok sosial. Dukungan peluang 19,94 kali untuk anggota keluarga yang mengalami gangguan jiwa patuh minum obat. Hal ini sesuai dengan hasil penelitian Kikkert et al, (dalam Fakhrudin, 2012) yang berpendapat bahwa kepatuhan minum obat pada pasien skizofrenia dapat dipengaruhi berbagai faktor antara lain, dukungan keluarga terhadap pasien.

Keluarga merupakan bagian 
keluarga merupakan salah satu sumber dukungan sosial yang sangat dibutuhkan anggota keluarga yang mengalami gangguan jiwa. Keluarga sebagai sumber dukungan sosial dapat menjadi bagian yang penting dalam penyembuhan penderita gangguan jiwa (Kumfo, dalam Viedeback, 2008). Individu yang mendapat sosial terbukti lebih sehat daripada individu yang tidak dapat dukungan sosial (Buchanan, 1995). Pasien yang tinggal sendirian secara umum mempunyai angka kepatuhan yang rendah dibanding mereka yang tinggal dalam lingkungan yang mendukung (Fleischacker, 2003).

Dukungan keluarga terdiri dari empat bentuk dukungan yaitu dukungan instrumental, emosional, informasional, dan penilaian (Bart, 1994). Pada penelitian ini bentuk dukungan yang diberikan keluarga pada anggota yang mengalami gangguan jiwa adalah dukungan instrumental, emosional, dan informasional. Berikut ini akan dijelaskan upaya yang dilakukan oleh keluarga berdasarkan bentuk dukungan yang diberikan.
Dukungan

instrumetal

merupakan dukungan yang diberikan secara langsung oleh keluarga untuk memenuhi kebutuhan perawatan kesehatan anggota keluarga yang mengalami gangguan jiwa. Pada penelitian ini dukungan instrumental yang dilakukan keluarga yaitu dengan menyiapkan obat, melakukan pengawasan minum obat, membujuk jika pasien tidak mau minum obat, dan memenuhi kebutuhan finansial.

Penyediaan dana merupakan salah satu bentuk dukungan instrumental. Dukungan finansial diberikan dengan memenuhi kebutuhan pasien untuk membeli obat dan membayar perawatan pasien di rumah sakit. Sesuai dengan pendapat Donel, dkk (2003) bahwa salah satu dukungan yang harus dipenuhi keluarga yang memiliki anggota keluarga yang mengalami skizoprenia adalah dukungan materi, khususnya untuk biaya pengobatan dan perawatan di rumah sakit.

Dukungan emosional berupa ungkapan kasih sayang, empati dan sikap menghargai sangat dibutuhkan pasien skizoprenia. Pada penelitian ini bentuk dukungan emosional yang 
diberikan oleh keluarga yaitu merawat dengan kasih sayang, dan menanggapi permasalahan yang dihadapi pasien.

Bentuk dukungan

informasional yang diberikan oleh keluarga dalam penelitian ini yaitu : memberikan informasi pada pasien tentang cara minum obat dan keluarga juga selalu menyakinkan pasien bahwa dengan minum obat yang teratur dapat menyembuhkan penyakit pasien. Keluarga yang memiliki pengetahuan yang adekuat, maka keluarga akan melakukan upaya yang maksimal untuk mengatasi ketidakpatuhan sedini mungkin. Untuk itu tenaga kesehatan harus mampu memberikan informasi yang jelas terkait dengan perilaku yang harus dilakukan oleh pasien dan keluarga. Selain itu tenaga kesehatan juga harus memberikan motivasi pada pasien dan keluarga agar berperilaku patuh terhadap saran kesehatan.

Hasil penelitian ini juga menunjukkan bahwa ada 8 responden $(12,1 \%)$ yang mendukung namun tidak patuh minum obat. Dimana responden memiliki pemahaman bahwa obat diberikan hanya berdasarkan gejala yang muncul dengan alasan agar obat yang seharusnya habis dalam dua minggu bisa dipergunakan dalam jangka waktu yang lama. Hal ini terjadi karena pengetahuan responden tentang program pengobatan pada pasien gangguan jiwa masih kurang. Pengetahuan yang kurang pada responden bisa terjadi karena responden kurang mendapat informasi dari fasilitas kesehatan. Fasilitas kesehatan merupakan sarana penting dimana tenaga kesehatan dapat memberikan penyuluhan terhadap keluarga tentang pentingnya terapi farmakologi yang dijalani pasien. Mc Gaslan (1994) dan Huxlery, dkk (2000) dalam Frisch \& Frisch (2006) menyatakan bahwa pemberian pengetahuan tentang gangguan jiwa dan terapi psikofarmaka pada keluarga akan meningkatkan kepatuhan dan menurunkan angka kekambuhan.

\section{Simpulan}

Hasil penelitian menunjukkan bahwa 66 responden $(81,5 \%)$ memberikan dukungan, dan 15 responden $(18,5 \%)$ tidak mendukung anggota keluarga yang mengalami gangguan jiwa. Hal ini menunjukkan bahwa sebagian besar keluarga memberikan dukungan terhadap 
anggota keluarganya yang mengalami gangguan jiwa.

Kepatuhan minum obat dari hasil penelitian menunjukkan bahwa 62 responden $(76,5 \%)$ menyatakan anggota keluarga yang mengalami gangguan jiwa patuh minum obat, dan 19 responden $(23,5 \%)$ menyatakan tidak patuh minum obat.

Berdasarkan uji statistik hasil penelitian menunjukkan terdapat hubungan yang bermakna antara dukungan keluarga dengan kepatuhan minum obat pada anggota yang mengalami gangguan jiwa dengan nila $\mathrm{p}=0.000$, yang artinya semakin baik dukungan keluarga terhadap anggota keluarganya yang mengalami gangguan jiwa maka anggota keluarga yang mengalami gangguan jiwa akan patuh minum obat sehingga dapat mempercepat proses penyembuhan. Hasil analisis diperoleh nilai OR 19,94 artinya keluarga yang memberikan dukungan memiliki peluang 19.94 kali untuk anggota keluarga yang mengalami gangguan jiwa patuh minum obat.

\section{Daftar Pustaka}

Buchanan, J. (1995). Social Support and schizoprenia : A review of the literature. Archieves of Psychiatric Nursing. Vol. IX No.

http://www.sciencedirect.com diakses pada tanggal 15 Februari 2013

Depkes RI, (2008). Profile Kesehatan Indonesia. Jakarta

Fakhrudin, (2012). Hubungan dukungan sosial dengan kepatuhan minum obat penderita skizoprenia di Kabupaten Aceh Barat, UGM, Yogyakarta.

Fleischhacker, W., Oehl, M.A \& Hummer, M. (2003). Factors influencing compliance in Schizophrenia patients. Journal Clin Psychiatry

Keliat, (1996). Peran serta keluarga dalam perawatan klien gangguan jiwa. Jakarta, EGC 
Prabowo, A. (2010) 50 persen pasien skizofrenia kambuh.

http://adhyatmanprabowo.word

press.com diakses pada tanggal

15 Februari 2013

Viedebeck,S.L.,(2008). Buku Ajar

Keperawatan Jiwa. Jakarta :

EGC 